Brit. J. vener. Dis. (1956), 32, 251.

\title{
ORAL PHENOXYMETHYL PENICILLIN IN ACUTE MALE GONORRHOEA*
}

\author{
BY \\ L. P. SHEIL \\ St. Thomas's Hospital, London, S.E.1
}

Between December 1, 1955, and February 16, 1956, 28 male patients with acute gonorrhoea were treated with phenoxymethyl penicillin (Penicillin V) administered orally. The dosage used was two pulvules $(400,000$ i.u.) three times a day for 3 consecutive days, i.e. 3.6 mega units for 3 days at the rate of 1.2 mega units daily. This was the dosage of benzethacil penicillin suggested by Bayne, Gylfe, Carfagno, and Boger (1953). Two patients, however, received only 1.2 mega units, one of these defaulted on the second day of treatment, and the other returned later and was followed up. This treatment was combined with daily urethral irrigations of $1 / 8000$ potassium permanganate for 14 days.

The series comprised 23 white patients and five coloured (four Jamaican and one Cingalese). Their average age was $31 \cdot 13$ years (oldest 44 ; youngest 20); eighteen were single and ten were married, one of whom was divorced. Nine of the patients had had previous attacks of acute gonorrhoea, the total number of admitted infections being 24 (maximum six, minimum two per patient). It was the first infection of the remaining nineteen patients. Two of the patients had been treated for syphilis in the past. One patient in the series had been infected by rectal contact with a male; of the remainder, 25 admitted recent sexual intercourse, and two refused to admit to having had any intercourse with either male or female. The average incubation period was 7 days (longest 26 days and shortest one day). The average duration of urethral discharge before treatment began was $2 \frac{1}{2}$ days (longest 14 days, shortest one day). The Wassermann and Kahn reactions were negative in all patients except one Jamaican, in whom both the Wassermann and Kahn reactions were strongly positive.

The gonococcal complement-fixation test before treatment was negative in 23 patients, doubtfully positive in two, and strongly positive in three. Diag-

* Received for publication, July 30, 1956. nosis was made on microscopy of a stained urethral smear in every case. Only one patient failed to report on the next day; the remaining 27 were followed for from 2 to 115 days. Smears were ordered on the second, third, and fourth days after treatment began; this, however, was not always possible as the discharge had frequently ceased by the second day. All smears examined were negative for the gonococcus with the exception of one in a patient who had been reinfected. Twenty prostatic beads were obtained from 21 to 91 days after treatment; 17 were normal, two showed the presence of pus, and one contained gonococci. Subsequent gonococcal complementfixation tests were obtained in 17 cases from 20 to 100 days after the commencement of treatment and fifteen remained negative.

Toxic Manifestations. - One patient complained of looseness of stools. There were no other toxic effects.

\section{Discussion}

Altogether 102 male patients with acute gonorrhoea were treated by intramuscular penicillin (Prolopen 500,000 stat) during the same period in this clinic. Of these, two relapsed with gonococci in subsequent prostatic beads. This short series of cases suggests that, in the dosage given, oral Penicillin $\mathrm{V}$ is as effective as parenteral penicillin in the treatment of acute gonorrhoea in the male. This series seems to show better results than those of Marmell and Prigot (1955) in the U.S.A., in which, however, a much lower dosage was used.

It is stressed, however, that the oral treatment of acute gonorrhoea should only be carried out under expert supervision and where there are adequate facilities for pathological investigation which should include serological tests for syphilis. Adequate surveillance must be ensured and the possibility of suppressing incubating early syphilis has always to be considered. 


\section{Summary and Conclusions}

(1) 28 male patients suffering from acute gonorrhoea were treated with oral Penicillin V: 25 had 3.6 mega units in divided doses over 3 days, while two had 1.2 mega units in one day, and one had 2.4 mega units over 2 days.

(2) 27 patients were followed for from 1 to 115 days. One patient was re-infected. In no other instance did a visible urethritis recur, but one patient relapsed with gonococci in the prostatic smear.
(3) Penicillin $V$, in the dosage indicated, appears to be effective treatment for acute gonorrhoea in the the male.

I wish to thank Dr. T. Anwyl-Davies and Dr. C. S. Nicol for their help in preparing this article.

\section{REFERENCES}

Bayne, G. M., Gylfe, J., Carfagno, S., and Boger, W. P. (1953). Amer. J. med. Sci., 225, 190.

Marmell, M., and Prigot, A. (1956). In "Antibiotics Annual, 19551956", ed. H. Welch and F. Marti-Ibañez, p. 518. Medical Encyclopedia, New York. 